\title{
Vegetables contamination by Parasitic Helminth Eggs in Malaysia and Indonesia
}

\author{
Reashnaa Loganathan, ${ }^{1}$ Ridad Agoes, ${ }^{2}$ Insi Farisa Desy Arya ${ }^{3}$ \\ ${ }^{1}$ Faculty of Medicine Universitas Padjadjaran, ${ }^{2}$ Department of Microbiology and Parasitology \\ Faculty of Medicine Universitas Padjadjaran, ${ }^{3}$ Department of Public Health, Faculty of Medicine, \\ Universitas Padjadjaran
}

\begin{abstract}
Background: Soil-transmitted helminth infection is known to be a serious issue in South East Asia when the farmers use night soil and contaminated water for their plants. In Indonesia, some of the farmers still use human feces and sometimes also mixed it with urine from the latrines as fertilizers. On the contrary, in Malaysia these contamination occured at a lower rate due to strict rules by the authorities. The objective of this study was to identify the helminth eggs in vegetables from traditional markets in Indonesia and Malaysia.

Methods: Three traditional markets were selected by non-random sampling, namely Pasar Ampang in Malaysia and 2 traditional markets in Indonesia, i.e Pasar Tanjungsari and Jatinangor. Cabbages and lettuce were bought from 15 different vegetable sellers per market. The samples were examined at the laboratory of the Medical Faculty, Universitas Padjadjaran. The method to obtain the specimen was in accordance with Khairul Anwar and Ramachandran. This study was carried out from July to October 2014. The collected data was analyzed by percentage and frequency tabulation.

Result: Most of the samples are contaminated by helminth eggs. In Pasar Ampang, 13.3\% in cabbage and $6.7 \%$ in lettuce. In Pasar Tanjung Sari, $46.7 \%$ in cabbage and $40 \%$ in lettuce. Moreover, in Pasar Jatinangor, $33.3 \%$ in cabbage and $26.7 \%$ in lettuce. Most of the helmint eggs were Ascaris lumbricoides.

Conclusions: The helminthes eggs contamination is higher in Indonesian traditional markets compared to in Malaysia. [AMJ.2016;3(2):190-4]
\end{abstract}

Keywords: Ascaris lumbricoides, Brasicca oleracea (cabbage), contamination, Lactuca sativa (lettuce), traditional markets

\section{Introduction}

Soil transmitted infection is known to be very common by consuming food, especially fruits or vegetables that has not been properly washed. Contaminated vegetables play a major role in the transmission of helminths. This is due to the usage of sewage water for watering the plants by the farmers and natural fertilizers. ${ }^{1}$ Different farmers have different ways of cultivating plants. Some farmers use natural fertilizers like animal feces however, some others use synthetic fertilizers. The vegetables prone to the usage of natural fertilizers are more likely to be contaminated. ${ }^{2}$ Furthermore, the vegetables vendors in some Indonesian markets claimed that the farmers from whom they bought the vegetables, used human feces and sometimes also mixed them with urine from the latrines as fertilizers. ${ }^{3}$ These farmers did not have enough money to buy chemical fertilizers. On the contrary, in Malaysia these contamination occured at a lower rate due to strict rules by the authorities. ${ }^{4}$

These fecal materials are the object of parasitic eggs contamination such as Ascaris lumbricoides, Trichuris trichura, Necator americanus Ancylostoma duodenale and others. ${ }^{2}$ When these eggs are left for a period of time, the eggs will mature and reach its infective stages which may cause helminth infection. ${ }^{5,6}$ The objective of this study was to identify the helminth eggs contamination in vegetables bought in traditional markets in Indonesia and Malaysia.

\section{Methods}

Three respective traditional markets were selected using the non-random sampling,

Correspondence: Reashnaa Loganathan, Faculty of Medicine, Universitas Padjadjaran, Jalan Raya Bandung-Sumedang Km.21, Jatinangor, Sumedang, Indonesia, Phone: +6283820568730 Email: reash1992@hotmail.com 
namely Pasar Ampang in Malaysia and 2 traditional markets in Indonesia, i.e Pasar Tanjungsari and Jatinangor. Then, cabbages and lettuce were bought from these three respective markets, consisting of 50 grams of each vegetable from 15 different vegetable vendors. The locations of vegetable planting were traced by the vendors. The samples bought in Pasar Ampang, Malaysia were packed with zip lock bags then sealed with a plastic bag. They were then kept in the refrigerator and examined two days later. The samples from the other two markets were immediately brought to the laboratory of the Faculty of Medicine, Universitas Padjadjaran to be examined. They were kept in a large basin and chopped into small pieces then washed with $500 \mathrm{ml}$ of $0.95 \%$ normal saline. The water used to wash the vegetables was collected in beakers. Next, the water in both beakers were mixed and kept aside for 20 minutes to allow sedimentation. Then, the top layer of the water was discarded and the suspension was kept. It was used to fill up 15 centrifuge tubes for each vegetable and centrifugation was performed. It was centrifuged at 2,000 rpm for 5 minutes. Subsequently, the supernatant was discarded and the residue was used for microscopic examination. A drop of the residue was placed on a slide with a glass cover. Microscopic examination was then carried out. The samples had been inspected qualitatively to identify if the samples observed have given a positive or negative result. ${ }^{7}$

This study was carried out from July to October 2014. Ethical clearance was given for this study. The method used in this study was similar to the method prescribed by Anwar and Ramachandran in their previous study. ${ }^{7}$

\section{Results}

Prior to the purchase of vegetables, the author personally interviewed the vegetable vendors in all three markets. The vegetables sold in Tanjung Sari market were grown by the farmers themselves. When enquired about how they kept the vegetables fresh, the farmers claimed that they used ditch -water. This ditch was flowing in the market itself and was connected to almost all the stalls in the market. Thus, there was a possibility that every stall in the market disposed rubbish and waste material in the ditch throughout the buying and selling process in the market. The water flowing in the ditch also came from the nearby housing area. The farmers argued that they only used the water when it looked clear. They also claimed that there was not a common tap for the use of everyone. Although there was a tap at the main entrance, it was time consuming to collect water with a pail and walk up to their stall.

Some of the vegetable vendors in Pasar Jatinangor mentioned that they used well -water to wash the vegetables at home before selling them in the market. However, when in the market, they still used ditch- water to keep the vegetables fresh. Some of them still used ditch water throughout the whole process. One vegetable vendor mentioned that he used tap water since his stall was near the tap in front of the market.

In Pasar Ampang, every vegetable stall where the samples were bought had their own tap. This was one of the steps taken by the Dewan Bandaraya Kuala Lumpur of the state government of Wilayah Persekutuan state. They play an important role in maintaining cleanliness in the market. A few workers were in charge of cleaning the markets every day after they were close, and for this service each stall will have to pay a particular sum of money at the end of each month.

Based on the results of this study, it can be deduced that from the respective selected traditional markets, all of thevegetables were contaminated by helminth eggs. Moreover, the cabbage (Brasicca oleracea) had a higher contamination of soil -transmitted helminths compared to the lettuce (Lactuca sativa).

The different species of soil -transmitted helminths eggs which had been found: in cabbage and lettuce were Brasicca oleracea, Ascaris lumbricoides, Hookworm, Trichuris trichura and other (in cabbage), and Brasicca oleracea, Ascaris lumbricoides, Trichuris

Table 1 Percentage of contamination of helminth eggs in 15 samples of cabbage (Brasicca oleracea) and Lettuce (Lactuca sativa)

\begin{tabular}{lccc}
\hline \multicolumn{1}{c}{ Type of Vegetables } & Pasar Ampang & Pasar Tanjung Sari & Pasar Jatinangor \\
\hline Cabbage (Brasicca oleracea) & $13.3 \%$ & $46.7 \%$ & $33.3 \%$ \\
Lettuce (Lactuca sativa) & $6.7 \%$ & $40 \%$ & $26.7 \%$ \\
\hline
\end{tabular}


Table 2 Distribution of soil -transmitted helminths eggs in Cabbage (Brasicca oleracea) and Lettuce (Lactuca sativa)

\begin{tabular}{lccc}
\hline \multicolumn{1}{c}{ Species } & Pasar Ampang & Pasar Tanjung Sari & Pasar Jatinangor \\
\hline Cabbage (Brasicca oleracea) & 2 & 4 & 5 \\
Ascaris lumbricoides & - & 1 & - \\
Hookworm & - & 1 & - \\
Trichuris trichiura & - & 1 & - \\
Others & & & 3 \\
Lettuce (Lactuca sativa) & 1 & 5 & - \\
Ascaris lumbricoides & - & - & - \\
Hookworm & - & 1 & 1 \\
Trichuris trichiura & - & - & \\
Others & & & \\
\hline
\end{tabular}

trichura and other (in lettuce) (Table 2, 3).

The most helminths eggs detected were Ascaris lumbricoides, followed by Trichuris trichiura and hookworm (Table 2).

\section{Discussion}

Although Malaysia is a developing country, soil -transmitted helminth infections still exist. This can be deduced based on the study conducted by Anwar and Ramachandran, ${ }^{7}$ which identified the prevalence of soil -transmitted helminths among lettuce leaves sold in local markets in Penang, Malaysia. The study has been carried out in 12 different markets in Penang, Malaysia. All of these markets showed a high contamination with Ascaris lumbricoides. However, there were also contamination with hook worms, Trichuris trichura and other species of soil -transmitted helminths. The similarity to this study was the high number of contamination with Ascaris lumbricoides which was detected in both kinds of vegetables.

Another study was carried out in Barru, Sulawesi, Indonesia to identify the intestinal helminth infections. This study showed that people were highly infected with Trichuris trichuria8 and Ascariasis lumbricoides. Infection reduces with people who are highly educated, and the farmers were people who were not educated properly. Hence, they were unaware of the infection which can be caused by night soil. ${ }^{9}$

In Pasar Ampang, helminth eggs contamination was low compared to the 2 traditional market in Indonesia. This is probably due to the strict action of the Dewan
Bandaraya state government in keeping the markets clean during and after the operational hours. The presence of a tap in each stall enhances the cleanliness of the vegetables as it can be washed more often with a clean source of water. However, there is still a slight contamination due to the carelessness of the stall keeper in not cleaning the vegetables thoroughly under the running water as the vegetables are washed in bulk and not one by one. Therefore, there is a possibility that the eggs do not fall off the vegetables. Moreover, the District Health Department plays an important role in checking on the fertilizers used for cultivating the vegetables in Malaysia. The results show that not all farmers are competent in using fertilizers free of fecal material throughout the whole process. The watering system of plants in the whole of Malaysia is controlled by Indah Water. This company is responsible in only providing water that has gone through the processes in the water plant to produce clean water for consumption. The farmers have been given a subsidy so that they can use it to water their plants at a lower price.

The government of Malaysia has taken many steps to increase the cleanliness level of the vegetables sold in the market and to reduce the parasitic helminth infection. However, there were some black dots which caused the continuous presence of infection with parasitic helminths.

Based on the study of Anuar and Salleh the two main risk factors found to be associated with hookworm infection was consuming raw vegetables and eating contaminated fresh food. Infections with Ascaris lumbricoides and 
Trichuris trichura are age dependent and the infections are mostly seen in communitiesaged lesser than 15 years old, belonging to a large household members and of low socioeconomic background. ${ }^{10}$

Furthermore, the vegetables sold in both markets in Indonesia, Pasar Tanjung Sari and Pasar Jatinangor, showed a higher contamination of parasitic helminths eggs compared to Pasar Ampang. When comparing both Pasar Tanjung Sari and Pasar Jatinangor, Pasar Tanjung Sari showed a higher number of positive results. Pasar Tanjung Sari is known to be one of the biggest markets in Sumedang area. The presences of only one tap at the entrance of the market hascaused more farmers to use the ditch water to keep the vegetables fresh. The ditch water may contain fecal material which will increase the contamination with the soil -transmitted parasitic helminth. On the other hand, Pasar Jatinangor is a smaller market compared to Pasar Tanjung Sari. Here, the distance from the main tap at the entrance is not too far. Therefore, more farmers from Pasar Jatinangor use clean water from the tap to keep the vegetables fresh. Only those who have their stalls at a further distance from the main tap may use ditch water. Thus, this might explain why Pasar Tanjung Sari had a higher contamination with soil -transmitted parasitic helminthes compared to Pasar Jatinangor. Some of the vendors in Pasar Jatinangor claimed that they purchased their vegetables in Pasar Tanjung Sari. However, these vegetables were washed again before being sold in Pasar Jatinangor. Most of the vendors used the existing tap water for washing the already contaminated vegetables. Although the vegetables were washed and cleaned again, they have a lesser number of positive results.

The vendors claimed that the officials from the Health Ministry occasionally carried out their rounds. This enabled the farmers to use human excreta and other animal excretes as manure for their plants since this was the cheapest and most convenient way to obtain fertilizers. The farmers also came from low socioeconomic background, so that, they could not afford to buy expensive fertilizers. To water the plants they used water from the river which was also dirty. The vendors claimed that the river water was known to be clean since it originated from the hills. However they failed to understand that many people uses the river water for domestic purposes. People use it for cleaning, washing and people also openly defecate in the river. This causes the water to be highly contaminated.
In this study, the limitation is the difficulty in identifying of the eggs since the Ascaris lumbricoides eggs looked similar to the Dicrocoelium dendriticum eggs at a glance.

It can be concluded that soil -transmitted helminths exist in both vegetables. The cabbage is more contaminated with soil -transmitted helminths than the lettuce. Ascaris lumbricoides, Trichuris trichura, hookworms and others have been found in the samples.

\section{References}

1. Al-Megrin WAI. Prevalence of intestinal parasites in leafy vegetables in Riyadh, Saudi Arabia. Int J Trop Med. 2010;5(2):203.

2. Daryani A, Ettehad G, Sharif M, Ghorbani L, Ziaei H. Prevalence of intestinal parasites in vegetables consumed in Ardabil, Iran. Food Control. 2008;19(8):790-4.

3. Abougrain AK, Nahaisi MH, Madi NS, Saied MM, Ghenghesh KS. Parasitological contamination in salad vegetables in Tripoli-Libya. Food Control. 2010;21(5):760-2.

4. Zeehaida M, Zairi N, Rahmah N, Maimunah A, Madihah B. Strongyloides stercoralis in common vegetables and herbs in Kota Bharu, Kelantan, Malaysia. Trop Biomed. 2011;28(1):188-93.

5. Mennan S, Handoo ZA. Plant-parasitic nematodes associated with cabbages (Brassica oleracea) in Samsun (Middle Black Sea Region), Turkey. Nematropica. 2006;36(1):99-106.

6. Donkur K, Lundberg S. Trichuris Trichiura (Whipworm) Infection (Trichuriasis). New York: Medscape; 2011. [cited: 2014 February 11] Available from: http:/ / emedicine.medscape.com / article/788570-overview.

7. Anuar AK, Ramachandran CP. A study on prevalence of Soil transmitted helminths among lettuce leaves sold in local markets in Penang, Malaysia. Med J Malaysia. 1977;31(4):262-5.

8. Haburchak DR, Dhawan VK, Watson CM. Hookworms disease. 2011 [cited 2014 February 11]. Available from: http: / / emedicine.medscape.com / article/218805-overview.

9. Toma A, Miyagi I, Kamimura K, Tokuyama Y, Hasegawa H, Selomo M, et al. Questionnaire survey and prevalence of intestinal helminthic infections in Barru, Sulawesi, Indonesia. Southeast Asian J Trop Med 
Public Health. 1999;30(1):68-77.

10. Anuar TS, Salleh FM, Moktar N. SoilTransmitted helminth infections and associated risk factors in three Orang Asli Tribes in Peninsular Malaysia. Scientific Reports. 2014;4(4101):1-7 